\title{
S5ynthesis
}

International Scientific Conference of IT and Business-Related Research

\section{ZASTUPLJENOST MASOVNIH OTVORENIH ONLAJN KURSEVA (MOOK) MEĐU STUDENTSKOM POPULACIJOM: REZULTATI PILOT ISTRAŽIVANJA}

\section{THE USE OF MASSIVE ONLINE OPEN COURSES (MOOCS) AMONG STUDENT POPULATION: THE RESULTS OF THE PILOT STUDY}

\author{
Ivan Stojšić1, Jelena Tomić ${ }^{1}$, Anđelija Ivkov-Džigurski ${ }^{1}$, Olja Maričić ${ }^{2}$ \\ ${ }^{1}$ Univerzitet u Novom Sadu, Prirodno-matematički fakultet, Novi Sad, Srbija \\ ${ }^{2}$ Univerzitet u Novom Sadu, Pedagoški fakultet u Somboru, Sombor, Srbija
}

\begin{abstract}
Apstrakt:
Internet je informacije i znanje učinio lako dostupnim svima, što je drastično povećalo mogućnosti za unapređenje obrazovanja svakog pojedinca. Masovni otvoreni onlajn kursevi (MOOK) su postali globalno prisutni u neformalnom i doživotnom obrazovanju miliona ljudi (u manjem obimu postali su i deo formalnog visokog obrazovanja, ukoliko matični univerzitet priznaje pomenuti kurs studenta). Poslednjih godina se značajno povećao broj institucija koje stvaraju MOOK. Mogućnosti za sticanje znanja, iskustava, veština i komuniciranje koje su stvorili MOOK nisu dovoljno iskorišćene i u realizaciji su uočeni problemi (kurseve uspešno završi manje od 10\% prijavljenih učesnika). Cilj ovog rada je da predstavi trenutno stanje u razvoju masovnih otvorenih onlajn kurseva i da prikaže rezultate pilot istraživanja u kojem je učestvovalo 83 studenta sa sedam fakulteta Univerziteta u Novom Sadu. Rezultati pokazuju da 53\% studenata nije znalo da MOOK postoje i da je samo 10,8\% studenata pohađalo ove kurseve. Svi studenti koji su pohađali kurseve su bili više nego zadovoljni. Istraživanje je nastavljeno kako bi se uključili i studenti sa drugih univerziteta i fakulteta u Srbiji. Autori smatraju da bi studente trebalo informisati i upoznati sa MOOK platformama, jer kroz ove kurseve studenti mogu proširiti znanje stečeno na fakultetu.
\end{abstract}

\section{Ključne reči:}

MOOK, učenje na daljinu, otvoreni obrazovni resursi, neformalno obrazovanje studenata.

\section{UVOD}

Koreni masovnih otvorenih onlajn kurseva (MOOK) se nalaze u ideji o otvorenom i svima dostupnom obrazovanju, shvatanju da znanje treba deliti besplatno i da želja za učenjem mora biti zadovoljena bez obzira na demografska, ekonomska i geografska ograničenja (Yuan \& Powell, 2013). Težnja ka otvorenom pristupu znanju uticala je i na mnoge vodeće svetske univerzitete koji su prvo počeli da postavljaju predavanja i materijale sa kurseva u otvorenom pristupu, a od 2011. godine pojavljuju se u značajnijem broju besplatni onlajn kursevi, poznati kao $M O O K$ i platforme (provajderi) na kojima se oni mogu pohađati (Filipi Matutinović, 2014). Moglo bi se reći da se MOOK razvijaju već od 2000. godine, ali tada nisu imali taj naziv i razvijali su se u okviru projekata kao što su: OpenCourseWere, OpenLearn, Open Source Softwere i drugi (Yuan \& Powell, 2013).

Naziv MOOK (massive open online course) - masovni otvoreni onlajn kurs je nastao 2008. godine kada je Dave Cormier upotrebio ovaj termin da opiše kurs „Connectivism and Connec-

\section{Abstract:}

The Internet has made information and knowledge widely and easily accessible, which significantly increased the possibilities for improving education of each individual. Massive Online Open Courses (MOOCs) have become globally present in informal and lifelong education of millions of people around the globe, and to a lesser extent, these types of courses have become part of formal undergraduate and graduate programmes, provided that such courses are recognized by the university. There has been a significant increase in the number of institutions offering MOOCs over the past few years. However, the opportunities to gain knowledge, experience, communication and other necessary skills via MOOCs are not fully utilized due to numerous limitations (less than $10 \%$ of participants successfully completed such online courses). The aim of this paper is to present the current situation in developing MOOCs and to present the results of the pilot study, involving 83 students from seven faculties of the University of Novi Sad. The results show that $53 \%$ of students have never heard of MOOCs, while only $10,8 \%$ of students attended such courses. Moreover, the survey indicates that students had numerous benefits from attending such courses. The research was continued in order to take into consideration the results of the survey at other universities and faculties in Serbia. The authors believe that students should be provided with more information about MOOC platforms, since such courses enable students to expand knowledge gained at their faculties.

\section{Key words:}

MOOC, distance learning, open educational resources, informal student education.

tive Knowledge" koji je bio dostupan kako studentima Univerziteta Manitoba (koji su plaćali školarinu i za koje je kurs donosio kredite), tako i široj javnosti besplatno putem onlajn lekcija i internet foruma. Pored 25 studenata Univerziteta Manitoba za ovaj kurs se prijavilo preko 2.300 drugih studenata iz različitih delova sveta zainteresovanih za tematiku kursa, ali ovi studenti nisu dobili kredite po završetku kursa (Cormier \& Siemens, 2010; Yuan \& Powell, 2013; Stevanović, 2013).

Postoje različite definicije MOOK, ali zajedničko je da su u pitanju onlajn kursevi koji imaju slobodnu registraciju, odnosno ne postoje ograničenja pri prijavljivanju (McAuley et al, 2010; Clow, 2013) i koji omogućavaju učenje bez prostornovremenskih ograničenja, čime je stvorena mogućnost da široka baza korisnika ima pristup (Stevanović, 2013) kvalitetnom obrazovanju na visokoškolskom nivou koje je u najvećem delu besplatno.

Struktura MOOK je različita i zavisi od sadržaja i karakteristika silabusa, od potreba samog kursa i od odluke instruktora (profesora) koji kreira kurs. Pri pravljenju kursa naglasak 
se stavlja na odabir odgovarajućih sadržaja, sastavljanju jasnih uputstava, proizvodnji kvalitetnih videa i kreiranju prijateljskog interfejsa (Soffer \& Cohen, 2015). Studenti (polaznici kursa) kurs pohađaju na način koji je sličan tradicionalnim visokoškolskim onlajn kursevima, odnosno gledanjem predavanja, čitanjem predloženih materijala i literature, rešavanjem kvizova i testova, izvršavanjem postavljenih nedeljnih zadataka (što može uključivati i ocenjivanje i proveru radova drugih studenata) i učešćem u diskusijama i forumima (EDUCAUSE, 2013). Zapaža se i pojava da se studenti organizuju u lokalne grupe za učenje i da se komunikacija među učesnicima kursa razvija i kroz društvene mreže. Ključna karakteristika MOOK-a je njegova fleksibilnost i mogućnost da student sam odredi nivo do kog želi da učestvuje u kursu, takođe ne postoji ni spoljašnji pritisak da se kurs završi do kraja (Joseph \& Nath, 2013).

Danas postoji više od 50 provajdera (platformi) koje nude mogućnost da se preko njih postavljaju i pohađaju masovni otvoreni onlajn kursevi, a pregled najvećeg broja platformi i kurseva je dostupan putem sajta: www.MOOC-list.com (Filipi Matutinović, 2014). Neke od najvećih i najpoznatijih platformi su: Coursera, edX, Udacity, FutureLearn, OpenupEd, ivercity, ALISON, Canvas, Udemy i druge.

Sa preko 12,2 miliona registrovanih korisnika i 989 različitih kurseva koje je napravilo 117 univerziteta i drugih naučnih institucija Coursera ${ }^{1}$ je najveća platforma preko koje se mogu pohađati MOOK. Coursera je nastala tako što su profesori sa Stanforda, Andrew Ng i Daphne Koller, formirali obrazovnu organizaciju i specijalizovani sajt za onlajn kurseve na osnovu tehnologije za učenje na daljinu koja je bila već prisutna na njihovom univerzitetu (Stevanović, 2013).

Masovni otvoreni onlajn kursevi su različito oblikovani, ali se mogu izdvojiti dva pedagoška pristupa koja imaju najveći uticaj na to kako su kursevi konstruisani. Konektivistički masovni otvoreni onlajn kursevi (ili cMOOK) predstavljaju prvi pristup i ovi kursevi su zasnovani na istoimenoj teoriji učenja, a drugi pristup čine masovni otvoreni onlajn kursevi koji se baziraju na sadržaju i transmisiji informacija, odnosno na bihejviorističkom pristupu i obeležavaju sa xMOOK (Yuan \& Powell, 2013). Konektivizam je razvio Gerge Siemens, ova teorija je nastala pod uticajem teorija o socijalnom konstruktivizmu, teorije mreže i teorije haosa (Bulatović et al., 2012). Komunikacija među učesnicima i njihovo umrežavanje čine jezgro za izgrađivanje znanja u konektivizmu (Downes, 2007). Postojanje različitih društvenih mreža značajno je olakšalo i unapredilo mogućnosti organizovanja konektivistički konstruisanog MOOK-a (Stojšić \& Mijatov, 2014).

Istraživanja su utvrdila da ne postoji razlika u postignuću i obrazovnim ishodima među studentima koji su nastavu pratili na tradicionalan način na fakultetu i onih koji su pohađali onlajn kurs (Glance et al., 2013).

Promene koje su uvedene na platformama i u same masovne otvorene onlajn kurseve su odgovor na uočene probleme i nedostatke. Mogućnosti za sticanje znanja, iskustva, veština i komuniciranje koje su stvorili MOOK nisu dovoljno iskorišćene i u realizaciji su uočeni problemi, kao što su: izuzetno nizak procenat učesnika uspešno završi kurs, problemi vezani za težinu i sadržaj silabusa, dolazi i do frustriranosti određenog broja studenata koji ne mogu da se uklope i prilagode ovakvom načinu učenja i pohađanja nastave, a postavlja se i pitanje vrednovanja rezultata i sertifikata koji se dobijaju prilikom uspešno završenog kursa.

Broj studenata registrovanih na platformama koje pružaju mogućnost pohađanja MOOK se svakodnevno povećava kao i broj kurseva, ali udeo onih koji uspešno završavaju kurseve je sve manji i iznosi oko 7\% (Stevanović, 2014). Trenutno je taj

1 https://www.coursera.org procenat još manji i iznosi oko $4 \%$ za većinu kurseva (Werbach, 2015). Postoje kursevi na koje se prijavi i do 230.000 studenata (Stevanović, 2014), mada je prosek oko 33.000 (Kolowich, 2013).

Da bi smo detaljnije prikazali problem izuzetno malog broja onih koji uspešno završe kurseve prikazaćemo detaljnije statističke podatke za nedavno završen Coursera-in kurs „Gamification" (kurs je trajao 6 nedelja, od 26. januara do 8. marta 2015. godine). Za ovaj kurs se prijavilo 60.455 studenata iz 182 države i $82 \%$ studenata je već imalo završen neki nivo fakultetskog obrazovanja. Kurs je završio 3.581 student što je 5,9\% od broja registrovanih studenata (za uspešan završetak kursa bio je potreban rezultat veći od 70\%). Pohađanju kursa pristupilo je 44.178 prijavljenih učesnika (što je $66 \%$ od ukupnog broja prijavljenih). Većina studenata koja je pristupila pohađanju kursa je i pogledala znatan deo video materijala, dok je učešće u kvizovima bilo znatno manje, ali veće nego učešće u nedeljnim zadacima. Na forumu kursa bilo je postavljeno preko 9.000 postova i dato je preko 300 novih primera upotrebom \#Gamifyit na društvenim mrežama (Werbach, 2015). Statistički podaci sa ovog kursa idu u prilog istraživanjima koja pokazuju da među učesnicima postoji znatan broj onih koji žele samo da gledaju video materijale i onih koji žele da gledaju materijale i da učestvuju u kvizovima, ali ne i u nedeljnim pismenim zadacima. Obe ove kategorije učesnika iako ostvaruju određen obim aktivnosti na kursu ne uspevaju da skupe dovoljan procenat da uspešno završe kurs, odnosno da dobiju potvrdu ili sertifikat (Stevanović, 2014). Kod vrednovanja svakog MOOK-a potrebno je sagledati opseg i kvalitet komunikacija (na forumu kursa, grupama za učenje, društvenim mrežama i slično) koji je uspostavljen među studentima (učesnicima kursa), jer se znatan deo učenja odvija upravo na taj način (Stojšić \& Mijatov, 2014). Na osnovu svega iznetog zaključujemo da vrednovanje uspešnosti nekog MOOK-a ne možemo vršiti samo na osnovu toga koliki procenat studenata završi kurs.

Razlozi zašto samo mali broj studenata (polaznika kursa) uspešno završi MOOK do kraja su: ne postoji obaveza da se kurs završi i studenti mogu da učestvuju samo onoliko koliko žele (Joseph \& Nath, 2013), zatim nedostatak vremena i/ili motivacije može biti razlog zbog koga studenti ne završe kurs do kraja, a takođe istraživanja govore da ljudi najviše vole da se zabavljaju u slobodno vreme i većina ljudi ne gleda baš pozitivno na to da slobodno vreme provodi učeći (Stevanović, 2014). Problem frustracije se može objasniti pojavom osećaja preplavljenosti, anksioznosti i izgubljenosti koji se mogu razviti kod onih studenata koji se nisu adaptirali na način učenja i pohađanja nastave putem masovnih otvorenih onlajn kurseva. Analizom izdvojenih komentara na forumima i društvenim mrežama utvrđeno je da neprilagođeni studenti najčešće ističu: da sve rade sami i da ne postoji dovoljna uključenost i podrška profesora i da često ne znaju kako da dobiju ili nađu odgovor na određeno pitanje u vezi sa kursom; da se osećaju preplavljeni sadržajima i različitim načinima kroz koje se pohađaju aktivnosti na kursu što dovodi do toga da često ne znaju šta tačno treba da rade, a takođe mnogi učesnici pokušavaju da oforme ili da se priključe grupama za učenje kako bi lakše savladali sadržaje kursa i/ili rešili postavljene zadatke (Knox, 2014). Dobar način da se studenti adaptiraju predstavljaju početni ili demo kursevi, na primer edX ${ }^{2}$ ima početni kurs DemoX kroz koji se studenti upoznaju sa načinom kako da pohađaju kurseve na ovoj platformi. Često je i težina kursa razlog zašto kurseve završi mali broj studenta, tako je na primer Coursera-in kurs „The fall and rise of Jerusalem“ završilo samo $1,8 \%$ prijavljenih učesnika, jer nivo težine i sadržaj kursa nisu odgovarali predznanju i mogućnostima studenata (Soffer \& Cohen, 2015). Može se izdvojiti još razloga zašto studenti nisu 
motivisani da završe kurseve do kraja, ali jedan od najčešćih je i taj da studenti u najvećem broju slučajeva nisu u prilici da sertifikate iskoriste za sticanje kredita na njihovom matičnom fakultetu, a takođe dobar deo onih koji pohađaju kurseve su već završili fakultete tako da im sertifikati ili fakultetski krediti nisu ni potrebni.

Novine koje se mogu uočiti su: skraćivanje kurseva, više i nema kurseva koji traju preko 10 nedelja (i pomenuti kurs „Gamification“ je skraćen sa 12 na 6 nedelja), zatim povećava se broj kurseva koji su stalno otvoreni (trenutno Coursera ima 77 stalno dostupnih kurseva ${ }^{3}$, dok su na platformi $U d e m y^{4}$ svi kursevi stalno dostupni korisnicima), takođe uvedeni su i verifikovani sertifikati koji se plaćaju i koji se dobijaju po uspešnom završetku kursa, dok Coursera ima i specijalizacije koje se sastoje od nekoliko kurseva iz iste oblasti i izrade završnog projekta na kraju ${ }^{5}$. Platforme kao što su Coursera, edX i iversity su uvele mogućnost da se sertifikati povežu i prikažu na Linke$\operatorname{din}^{6}$ profilima studenata. Pojedine kompanije koriste MOOK da pronađu talentovane studente i da regrutuju nove zaposlene (Yuan \& Powell, 2013).

Dostupni podaci u kojima su analizirani pojedinačni kursevi pokazuju znatno veću prolaznost studenata koji plate kurs. Za Coursera-in kurs "What a plan knows"koji je ponudio Univerzitet u Tel Avivu (Tel Aviv University) 2013. godine se prijavilo 32.009 studenata, ali je kurs završilo samo 2.318 studenata, što je nešto više od $7 \%$, ali procenat onih koji su uspešno završili kurs među onima koji su platili kurs je 62,5\%, odnosno oko 9 puta bolje u odnosu na opštu prolaznost (Soffer \& Cohen, 2015). Stevanović (2013) ističe da je procenat prolaznosti među studentima koji plaćaju kurs oko 70\%. Isti autor ističe (2014) da ljudi više vrednuju ono što plate nego ono što dobiju besplatno, pa se na taj način može objasniti značajno veća prolaznost među studentima koji plaćaju kurs.

\section{REZULTATI I DISKUSIJA}

Pohađanje masovnih otvorenih onlajn kurseva je postalo globalno i korisnici nisu više samo fakultetski studenti. Istraživanja pokazuju da većinu prijavljenih čine osobe koje već imaju završen bar prvi nivo fakultetskog obrazovanja i da kurseve pohađaju zato što su zainteresovani za tematiku kursa i/ili radi profesionalnog usavršavanja (Belanger \& Thornton, 2013; Werbach, 2015). MOOK se u najvećem broju slučajeva prave da svojom težinom odgovaraju akademskom nivou osnovnih studija (mada sve više postaju interesantni kursevi namenjeni K12 učenicima) tako da i dalje značajnu ciljnu grupu čine fakultetski studenti (pokazalo se da su za kurseve posebno zainteresovani studenti na višim stepenima studija).

U istraživanju koje smo započeli želimo da otkrijemo stavove studenata u Srbiji o neformalnom obrazovanju, kao i da utvrdimo koliko su studenti upoznati sa masovnim otvorenim onlajn kursevima i koliki procenat studenata ih pohađa. Od studenata koji su pohađali masovne otvorene onlajn kurseve želimo da saznamo i koje platforme koriste, koliko kurseva su pohađali, šta ističu kao koristi od pohađanja ovih kurseva i koju bi ocenu dali MOOK na osnovu njihovog dosadašnjeg iskustva. Istraživanje je u toku i u ovom radu prikazujemo samo rezultate pilot istraživanja u kojem smo pre svega želeli da saznamo da li studenti znaju za MOOK i da li su pohađali iste. U pilot istraživanju je učestvovalo 83 studenta sa sedam fakulteta Univerziteta u Novom Sadu različitih godina i stepena studija koji su želeli da učestvuju u anketiranju. U polnoj strukturi uzorka preovlađuje

3 https://www.coursera.org/courses? courseType=v2.ondemand

4 https://www.udemy.com

5 https://www.coursera.org/specializations?utm_medium=topnav

6 https://www.linkedin.com ženski pol sa $69,9 \%$. Prosečna starost studenata je 24,65 godina $(\mathrm{SD}=3,750)$. Najmlađi student u uzorku ima 20 godina, a najstariji 47 , dok je $62,7 \%$ studenata mlađe od 25 godina, a $37,3 \%$ studenata ima 25 ili više godina. Kao što je ranije pomenuto, $\mathrm{u}$ istraživanju su učestvovali studenti sa sedam fakulteta Univerziteta u Novom Sadu i to: 5 studenata (6,0\%) Pravnog fakulteta, 7 studenata $(8,4 \%)$ Fakulteta tehničkih nauka, 8 studenata $(9,6 \%)$ Ekonomskog fakulteta, 12 studenata (14,5\%) Filozofskog fakulteta, 16 studenata (19,3\%) Medicinskog fakulteta, 17 studenata (20,5\%) Pedagoškog fakulteta u Somboru i 18 studenata (21,7\%) Prirodno-matematičkog fakulteta. Prema stepenu studija u istraživanju je učestvovalo: 40 studenata $(48,2 \%)$ prvog stepena studija (osnovne akademske studije), 14 studenata (16,9\%) prvog i drugog stepena studija zajedno (integrisane studije), 18 studenata $(21,7 \%)$ drugog stepena studija (master studenti) i 11 studenata $(13,3 \%)$ trećeg stepena studija (studenti doktorskih studija).

Rezultati pilot istraživanja pokazuju da je $47 \%$ studenata i pre ankete znalo da masovni otvoreni onlajn kursevi postoje, a 53\% studenata je kroz anketu prvi put saznalo za MOOK i platforme putem kojih mogu da pohađaju kurseve. Samo 10,8\% (9 studenata) je pohađalo MOOK. U većem broju istraživanja naglašava se da muškarci više pohađaju masovne otvorene onlajn kurseve (Stevanović, 2014). U našem uzorku primenom Pirsonovog hi-kvadrat testa nismo utvrdili da postoji statistički značajna razlika prema polu u odnosu na to da li student zna za MOOK $(\mathrm{p}=0,720)$ i da li je pohađao/la MOOK $(\mathrm{p}=0,078)$. Ne postoji statistički značajna razlika ni u odnosu na to da li student zna za MOOK ( $\mathrm{p}=0,269)$ i da li je pohađao/la MOOK $(\mathrm{p}=0,054)$ prema tome da li je student mlađi ili stariji od 25 godina. Treba istaći da je procentualno veći broj onih koji znaju za MOOK i koji su ih pohađali u grupi studenata starijih od 25 godina, ali razlika nije statistički značajna. Ukoliko posmatramo stepen studija i procenat studenata koji su pohađali kurseve uočavaju se određene razlike, ali razlike nisu i statistički značajne $(\mathrm{p}=0,155)$. Masovne otvorene onlajn kurseve je pohađalo $7,4 \%$ studenata osnovnih i integrisanih studija, 11,4\% studenata master studija i 27,3\% studenata doktorskih studija. Najveći broj studenata $(53,0 \%)$ je za masovne otvorene onlajn kurseve saznao upravo kroz ovo pilot istraživanje. Studenti koji su od ranije znali za MOOK su za njih saznali u najvećem broju putem pretrage interneta i u kontaktu sa kolegama ili prijateljima, samo 5 studenata je saznalo kroz obaveštenje na fakultetu ili u kontaktu sa profesorima/asistentima (tabela 1).

\begin{tabular}{|c|c|c|}
\hline Način saznanja & Broj studenata & $\%$ \\
\hline $\begin{array}{l}\text { 1. saznali su kroz upitnik } \\
\text { 2. saznali su pretragom } \\
\text { interneta }\end{array}$ & 44 & 53,0 \\
$\begin{array}{l}\text { 3. saznali su putem društve- } \\
\text { nih mreža }\end{array}$ & 18 & 21,7 \\
$\begin{array}{l}\text { 4. saznali su putem obavešte- } \\
\text { nja na sajtu univerziteta ili } \\
\text { fakulteta }\end{array}$ & 4 & 4,8 \\
$\begin{array}{l}\text { 5. saznali su od profesora ili } \\
\text { asistenta }\end{array}$ & 1 & 1,2 \\
$\begin{array}{l}\text { 6. saznali su od prijatelja ili } \\
\text { kolega }\end{array}$ & 83 & 100,0 \\
\hline$*$ Ukupno: & 6 & 12,0 \\
\hline
\end{tabular}

* u uvodnom delu upitnika objašnjen je pojam MOOK-a i dati su linkovi ka nekim od najvećih platformi putem kojih se kursevi mogu pohađati

Tabela 1. Kako su studenti saznali za MOOK 
Studenti koji nisu pohađali masovne otvorene onlajn kurseve $(89,2 \%$ od ukupnog uzorka) su se različito izjašnjavali na pitanje da li planiraju da pohađaju MOOK. Najveći broj studenata, odnosno njih 74,3\% se izjasnio da će možda pohađati kurseve, $14,9 \%$ da sigurno hoće, dok se $10,8 \%$ studenata izjasnilo da neće i da nisu zainteresovani.

Studenti koji su pohađali MOOK u najvećem broju slučajeva su koristili Coursera-inu platformu (tabela 2), mada treba istaći da $33,3 \%$ studenata ima profile na više platformi.

\begin{tabular}{|l|c|c|}
\hline \multicolumn{1}{|c|}{ Platforma } & Broj studenata & $\%$ \\
\hline 1. Coursera & 8 & 88,9 \\
2.iversity & 2 & 22,2 \\
3. Udemy & 1 & 11,1 \\
4.Canvas & 1 & 11,1 \\
5.edX & 1 & 11,1 \\
6. Druge manje platforme & 2 & 22,2 \\
\hline
\end{tabular}

Tabela 2. Platforme preko kojih studenti pohađaju MOOK

Prosečan broj kurseva koje su studenti pohađali je 3,67 $(\mathrm{SD}=4,00)$, dok je minimalan broj kurseva 1 , a maksimalan 12 . Prosečan broj završenih kurseva po studentu je $2,44(\mathrm{SD}=3,36)$, minimalna broj završenih kurseva je 0 , a maksimalan 10 . Procenat uspešno završenih kurseva varira od studenta do studenta, mada je prosek 66,5\% (studenti uključeni u pilot istraživanje su ukupno pohađali 33, a uspešno su završili 22 masovna otvorena onlajn kursa).

Svi studenti koji su pohađali MOOK su istakli da su imali koristi od njih i to najviše u vidu znanja (100\%) i novog iskustva (88,9\%). Samo 55,6\% studenata je izdvojilo dobijanje sertifikata/ potvrde o završenom kursu kao benefit pohađanja MOOK, a još u manjem procentu studenti su izdvajali uspostavljanje kontakta sa profesorima (predavačima) i drugim studentima (tabela 3).

\begin{tabular}{|l|c|c|}
\hline \multicolumn{1}{|c|}{ Benefiti } & Broj studenata & $\%$ \\
\hline $\begin{array}{l}\text { 1.novo iskustvo } \\
\text { 2.znanje }\end{array}$ & 8 & 88,9 \\
$\begin{array}{l}\text { 3. ovladavanje određenom } \\
\text { veštinom }\end{array}$ & 5 & 100,0 \\
$\begin{array}{c}\text { 4. uspostavljanje kontakta sa } \\
\text { profesorima (predavačima) }\end{array}$ & 3 & 33,3 \\
$\begin{array}{c}\text { 5.uspostavljanje kontakta i } \\
\text { komunikacija sa drugim } \\
\text { studentima }\end{array}$ & 1 & 11,1 \\
$\begin{array}{c}\text { 6. sertifikati/potvrde o } \\
\text { završenom kursu }\end{array}$ & 5 & 55,6 \\
\hline
\end{tabular}

Tabela 3. Koristi od pohađanja MOOK koje su izdvojili studenti

Studentima koji su pohađali MOOK je na kraju ankete data mogućnost da ocene (1-10) svoje iskustvo sa masovnim otvorenim onlajn kursevima, tako što ocena 1 označava da student nije uopšte zadovoljan i da MOOK ne nalazi korisnim, dok ocena 10 označava da su kursevi odlični za sticanje znanja, razvijanje veština i uspostavljanje novih kontakata. Prosečna ocena koju su studenti dali svom iskustvu sa masovnim otvorenim onlajn kursevima je 8,78 (SD=1,394), najniža ocena koju su studenti dali je 7, a najviša 10 .

$\mathrm{Na}$ osnovu rezultata može se zaključiti da je i samo pilot istraživanje doprinelo boljoj informisanosti studenta po pitanju mogućnosti neformalnog obrazovanja putem $\mathrm{MOOK}$. Kroz učešće u anketiranju u okviru pilot istraživanja 44 studenata prvi put je saznalo za MOOK i naučilo nešto o ovim kursevima kao značajnom otvorenom obrazovnom resursu. Treba istaći da otvoreni kursevi omogućavaju i predavačima i studentima prostor za razvoj veština, znanja i načina razmišljanja koji su im potrebni da učestvuju u kompleksnim, svakodnevno promenljivim realnim životnim situacijama u kojima je znati kako saznati jednako važno kao i znati (Cormier \& Siemens, 2010).

Rezultati koji se odnose na pohađanje MOOK se ne mogu generalizovati, jer je u uzorku pilot istraživanju udeo studenata koji su pohađali kurseve izuzetno mali. Dobijeni rezultati su ipak značajni jer daju indikacije i potvrđuju stavove autora da je potrebno informisati i upoznati studente sa mogućnostima pohađanja masovnih otvorenih onlajn kurseva. Takođe, svi studenti uključeni u pilot istraživanje koji su već pohađali MOOK ističu da postoje koristi od pohađanja ovih kurseva. Studenti pohađanjem MOOK (bez obzira na to da li završe kurs ili ne) dolaze do aktuelnih i savremenih informacija i znanja i na taj način mogu proširiti znanje koje stiču na matičnom fakultetu.

Istraživanje je nastavljeno putem elektronskog upitnika, kako bi se uključili i studenti drugih univerziteta i fakulteta u Srbiji. Cilj nastavka istraživanja je sa jedne strane informisanje studenata o postojanju masovnih otvorenih onlajn kurseva, a sa druge strane dobijanje podataka o zastupljenosti pohađanja MOOK kao vida neformalnog obrazovanja među studentskom populacijom u Srbiji.

\section{REZIME}

Internet i mobilne tehnologije su stvorile mogućnost da svaki pojedinac izgradi lični prostor za učenje, razmišljanje i komuniciranje (Stojšić \& Mijatov, 2014). Masovni otvoreni onlajn kursevi poseduju značajan potencijal za unapređenje obrazovanja studenata u savremenom visokom obrazovanju, jer im omogućavaju da putem interneta dolaze do novih znanja i informacija bez vremenskih i prostornih ograničenja, a pošto su kursevi u najvećem obimu besplatni ne postoje ni ekonomska ograničenja. Studentima se kroz MOOK pruža mogućnost da se usavršavaju iz onih oblasti koje izučavaju na fakultetu, ali i da steknu znanja koja su im potrebna i/ili koja žele da saznaju, a koja nisu uključena u kurikulume studijskih programa po kojima studiraju. Treba napomenuti da masovne otvorene onlajn kurseve mogu pohađati svi oni koji su zainteresovani za njih, odnosno ne postoje druga ograničenja osim jezičkih ili mogućnosti pristupa internetu, mada se i ova ograničenja svakim danom sve više prevazilaze jer se kursevi prevode na sve više jezika (na primer Coursera kao najveća platforma nudi kurseve na 30 jezika uključujući i nekoliko kurseva koji su dostupni i na srpskom jeziku ${ }^{7}$, a internet je već masovno i globalno dostupan. Masovni otvoreni onlajn kursevi predstavljaju značajan otvoreni obrazovni resurs koji se može koristiti u formalnom i neformalnom univerzitetskom/fakultetskom obrazovanju, doživotnom obrazovanju (odnosno u ličnom i profesionalnom razvoju), a takođe uočavaju se i druge primene, na primer pojedine kompanije koriste MOOK da regrutuju nove zaposlene, a srednjoškolci koriste kurseve da se upoznaju sa različitim disciplinama odnosno za profesionalnu orijentaciju i pomoć pri donošenju odluke šta da studiraju.

$\mathrm{U}$ realizaciji i upotrebi masovnih otvorenih onlajn kurseva su uočeni i određeni problemi i nedostaci. Najčešće se izdvajaju sledeći problemi: mali broj studenata završi kurseve do kraja, javlja se i frustracija kod određenog broja studenata koji ne mogu da se uklope u ovako organizovan način pohađanja nastave i učenja, a takođe prisutan je i problem vrednovanja rezultata i priznavanja sertifikata koji se dobijaju za uspešno završen kurs.

7 https://www.coursera.org/courses 
Određeni problemi su bili i očekivani jer su MOOK novina i neka vrsta revolucije u visokom obrazovanju, tako da ovi uočeni problemi imaju svoje razloge koje je moguće sagledati i donekle objasniti. Mali broj studenata završi kurseve jer ne postoji obaveza da se oni završe (studenti mogu da preuzmu i/ili pogledaju samo one lekcije i materijale koji ih zanimanju), zatim nedostatak motivacije može biti razlog zbog kog student ne završi kurs do kraja, a takođe postoje i istraživanja koja govore da ljudi ipak više vole da se zabavljaju nego da uče u svom slobodnom vremenu. Problem sa pojavom frustracije kod određenog broja studenata se može objasniti time što mnogi studenti nisu upoznati sa načinom učenja i pohađanja nastave putem masovnih otvorenih onlajn kurseva (zato na primer edX ima početni kurs DemoX kako bi upoznao studente sa načinom kako da pohađaju kurseve $^{8}$ ), često i težina kursa ne odgovara predznanju studenta (kursevi se najčešće prave na nivou težine fakultetskih kurseva i često su zahtevniji nego što su studenti prvobitno mislili da će biti). Može se izdvojiti još jedan razlog zašto studenti nisu motivisani da završe kurseve, a to je zato što sertifikati u najvećem broju slučaja nisu priznati na njihovom matičnom fakultetu/ univerzitetu i ne dobijaju kredite za nih, a takođe dobar deo onih koji pohađaju kurseve su već završili fakultete tako da im sertifikati ili fakultetski krediti nisu ni potrebni. Problem vrednovanja i priznavanja rezultata i sertifikata nije u potpunosti rešen, mada je primetno da platforme pokušavaju da povećaju značaj i vrednost svojih kurseva (mnoge platforme su uvele verifikovane sertifikate - za čije dobijanje je potrebno platiti i uspešno završiti kurs, dok Coursera ima i specijalizacije koje se sastoje od nekoliko kurseva iz iste oblasti i izrade završnog projekta ${ }^{9}$ ), takođe neke platforme (Coursera, edX i iversity) su uvele mogućnost da se sertifikati povežu i prikažu na Linkedin profilima korisnika (studenata).

S obzirom da većina studenata koji su učestvovali u pilot istraživanju (53\%) nije upoznata sa mogućnostima koje pružaju MOOK, neophodno je informisati i upoznati studente u Srbiji sa ovom mogućnošću, jer putem MOOK studenti mogu steći nova iskustva, znanja i veštine od profesora i predavača sa najprestižnijih fakulteta na svetu. U prilog tome da ima smisla pohađati MOOK govori i to da su svi studenti koji su učestvovali u pilot istraživanju, a koji su već pohađali MOOK istakli da su imali koristi od njih i to što su svoje iskustvo sa korišćenjem MOOK prilično visoko ocenili (prosečna ocena koju su studenti dali je 8,8/10).

\section{LITERATURA}

Belanger, Y., \& Thornton, J. (2013). Bioelectricity: A quantitative approach - Duke University's first MOOK. Durham: Duke University Libraries. Datum posete: 23.2.2015., dostupno na: http://dukespace.lib.duke.edu/dspace/bitstream/handle/10161/6216/Duke_Bioelectricity_MOOK_Fall2012. pdf?sequence $=1$

Bulatović, G., Bulatović, Lj., \& Arsenijević, O. (2012). Konektivizam kao teorijska osnova učenja na internetu. U: 4. Internacionalna konferencija: Tehnika i Informatika u Obrazovanju. 1-3. jun 2012. Čačak: Tehnički fakultet.

Clow, D. (2013). MOOK and the funnel of participation. In: Third Conference of Learning Analytics and Knowledge LAK 2013. 8-12 April 2013. Leuven, Belgium.

Cormier, D. \& Siemens, G. (2010). The Open Course - Through the Open Door: Open Courses as Research, Learning and Engagement. Educause Review, 45(4), 30-39.

8 https://www.edx.org/course/demox-edx-demox-1

9 https://www.coursera.org/specializations?utm_medium=topnav
Downes, S. (2007). What connectivism is. 20.1.2014. http://halfanhour.blogspot.com/2007/02/what-connectivism-is.html

EDUCAUSE. 7 things you should know about... MOOK II. 23.2.2015. https://net.educause.edu/ir/library/pdf/ELI7097. pdf

Filipi Matutinović, S. (2014). Naučne informacije u Srbiji: Protok, dostupnost, vrednovanje (3. izmenjeno i dopunjeno izdanje). Beograd. Datum posete: 23.2.2015., dostupno na: http:// kobson.nb.rs/upload/documents/oNamaPredavanja/PR2014TekstZaDoktorante.pdf

Glance, D., Forsey, M., \& Riley, M. (2013). The pedagogical foundations of massive open online courses. First Monday, 18(5). DOI:10.5210/fm.v18i5.4350.

Joseph, A. M., \& Nath, B. A. (2013). Integration of Massive Open Online Education (MOOK) System with in-Classroom Interaction and Assessment and Accreditation: An extensive report from a pilot study. In: Proceedings of the International Conference on e-Learning, e-Business, Enterprise Information Systems, and e-Government EEE'13 - WORLDCOMP'13. July 22-25, 2013 (103-111). Las Vegas Nevada: CSREA Press.

Knox, J. (2014). Digital culture clash: "massive" education in the E-learning and Digital Cultures MOOK. Distance Education. 35 (2), 164-177.

Kolowich, S. (2013). The Professors Who Make the MOOK. Datum posete: 20.10 .2014 , dostupno na: http://publicservicesalliance.org/wp-content/uploads/2013/03/The-Professors-Behind-the-MOOK-Hype-Technology-The-Chronicle-ofHigher-Education.pdf

McAulay, A., Stewart, B., \& Siemens, G. (2010). The MOOK model for digital practice. Charlottetown: University of Prince Edward Island. Datum posete: 18.2.2015., dostupno na: http://www.elearnspace.org/Articles/MOOK_Final.pdf

Soffer, T., \& Cohen, A. (2015). Implementation of Tel Aviv University MOOK in Academic Curriculum: A Pilot Study. International Review of Research in Open and Distributed Learning. 16 (1), 80-97.

Stevanović, N. (2013). Uspešnost MOOK u obrazovnim aktivnostima univerziteta. U: Zbornik radova IV naučnog skupa MREŽA 2013: Internet u edukacionom i poslovnom okruženju. 14.6.2013. godine (46-49). Valjevo: Poslovni fakultet Valjevo.

Stevanović, N. (2014). Effects of motivation on performance of students in MOOK. U: Sinteza 2014 - Impact of Internet on Business Activities in Serbia and Worlwide / Uticaj Interneta na poslovanje u Srbiji i svetu. 25-26.04.2014. (418-422). Beograd: Univerzitet Singidunum.

Stojšić, I., \& Mijatov, M. (2014). MOOK kao izvor znanja u visokom obrazovanju, studija slučaja: Coursera-in kurs: “Archaeology's Dirty Little Secrets”. U: Zbornik radova XX skup Trendova razvoja TREND 2014: Razvojni potencijal visokog obrazovanja. Kopaonik, 24-27.02.2014. (173176). Novi Sad: Fakultet tehničkih nauka.

Werbach, K. (2015). Gamification statistics spring 2015 [video]. Coursera \& University of Pennsylvania. datum posete: 23.3.2015., dostupno samo onima koji su pohađali kurs "Gamification" na: https://www.coursera.org

Yuan, L., \& Powell, S. (2013). MOOK and Open Education: Implication for Higher Education (A white paper). Bolton: University of Bolton, Centre for Educational Technology and Interoperability Standards (CETIS) \& JISC. Datum posete: 26.1.2014., dostupno na: http://publications.cetis. ac.uk/wp-content/uploads/2013/03/MOOK-and-OpenEducation.pdf 